\title{
Mountain science poised to help ecotourism in Peruvian cloud forests
}

\author{
Fausto O. Sarmiento', M.B. Bush², W. Church ${ }^{3}$, P. VanValkenburgh 4 , M. Oliva ${ }^{5}$, E. Delgado ${ }^{5}$, S. Fernandez and N. Rojas $^{5}$ \\ We seek to highlight how paleoecology, archaeology, and geoecology can add to the repertoires of ecotourism guides \\ in Peru's Chachapoya region, providing informed portraits of the history of cloud forest ecology in Peru's northeastern

\section{Andes and raising concerns about the future conservation of these mountainscapes under human impact.}

The eastern slopes of the Andes are underexplored and underexploited from the perspective of ecotourism. In the northern region of Chachapoyas (Fig. 1), where we have focused recent research, phenomenal biodiversity and pre-Hispanic cultural diversity are present in such proximity to each other that an ecotourist spending seven to 10 days on a single visit might encounter everything from mummies to marsupials. Biological and cultural diversity in these tropical montane cloud forests (TMCFs) have been, and continue to be, shaped by climate change; but scientists have largely missed the opportunity to engage guides and tourists, and to enrich their narratives and experiences while informing them on matters of montane conservation concern.

New research initiatives are improving our understanding of linkages between climate oscillations and how past human activities influenced modern trajectories of succession and community composition in Chachapoyas. Mountain geographers are now collaborating with paleoecologists and archaeologists to explore the origins of Anthropocene landscapes in the tropical Andes (Bush et al. 2015; Guengerich and Berquist 2020).

\section{Cloud forests as a transformed landscape} Until recently, the Andean-Amazon slopes were considered remote and inaccessible; a primordial wilderness. We now know that humans arriving by the end of the Pleistocene probably contributed to the extinction of megafauna (Raczka et al. 2018), and initiated 12,000 years of landscape domestication both deliberately and unintentionally, which varied in intensity through time and across space (Young 2009; Guengerich 2015). By the late Holocene, the Chachapoyas socioecological system had generated dense clusters of complex agricultural societies built atop heavily modified mountain landscapes, and became a trade crossroads. Valley systems provided natural east-west conduits and became foci of settlements (Åkesson et al. 2020; Church and von Hagen 2008; Lara 2010).

Between ca. 1200 CE and 1400 CE, a cultural tradition with shared attributes, including some elements of architectural and ceramic style, reached its peak across a settled area of ca. 30,000 km² (Schjellerup 2019). Termed "Chachapoyas culture" by archaeologists, the Inka first referred to the region as the "land of the people of the clouds" or sachapuyu, and this Kichwa name appears on the earliest colonial documents. A combination of demographic collapse, social disintegration, and lack of interest in the native cultures shown by Spanish colonists rapidly eliminated cultural knowledge, leaving the task of reconstruction to historical geographers, landscape archaeologists, historical ecologists and paleoecologists.

This is where new data on climate change are revealing unexpected patterns. Intense droughts immediately conjure images of hardship - possibly even landscape abandonment. But in these very wet settings, those droughts appear to have fueled agricultural incursions into cloud forest (Åkesson et al. 2020). Portions of the landscape were cleared for maize cultivation until wet conditions returned. Thus, the more accessible the cloud forest, the more likely it was to have supported past human activities. In large part, the factors that make a modern valley or ridge accessible to ecotourists also made it a usable space for past cultivators. Consequently, the areas that tourists can readily access today are very likely to have long histories of intensive land use, dating to pre-Columbian times (Sarmiento 2012) constituting de facto biocultural microrefugia.

\section{Cross-cutting science for montological studies}

Montology is the transdisciplinary science of mountains, where current geoecological knowledge, paleoecological insights, and archaeological studies in the region's TMCFs now complement one another. Pollen data obtained from lakes tell stories of climate extremes beyond our modern experience, both wet and dry, against a backdrop of long-term change. Pollen records collected from Lake Pomacochas (Bush et al. 2015) and Laguna de los Cóndores indicate millennia of maize cultivation, demographic and subsistence shifts, and ecological turnover before the Spanish invasion of 1532-35 CE (MatthewsBird et al. 2017). Within the last 1000 years, as regional climates became wetter, some locations show forest recovery apparently at the expense of cultivated lands, perhaps as land-use strategies have shifted toward exploiting drier slopes, the net effect of which was widespread forest recovery. Within the last 500 years, the Inka incorporation followed by the Spanish invasion and subsequent colonization, including the effects of epidemic diseases, decimated local cultures, and concentrated inhabitants in readily controlled centers of occupation, further emptying the forests of inhabitants. During the 20th century, accelerating population growth and enhanced accessibility have ignited new efforts to conquer the "wilderness" and resume landscape domestication (Schjellerup et al. 2005).

Another realization is that many TMCF Andean habitats that were long thought to be "natural" are now seen as having long histories of human modification or "engineered" landscapes, and that a reconsideration of their resilience to climate change is needed (Sarmiento 2016). Because fire was a part of past land management, it would have influenced survival rates and increased edge effects on unburned areas. The hunting

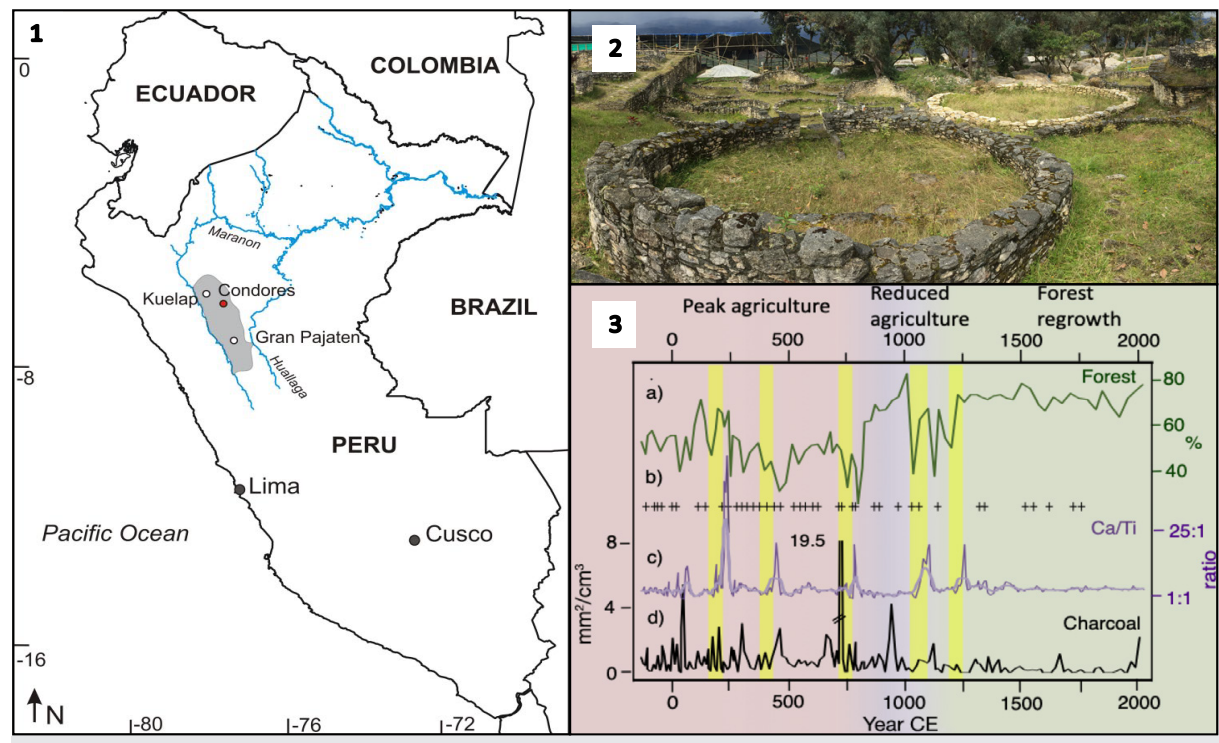

Figure 1: The Chachapoyan region. (1) Sketchmap showing the Chachapoyan region (grey shaded area), (2) Chachapoya house remains at Kuelap, (3) megadroughts (yellow bars from the Laguna de los Cóndores record): (A) percentage of forest pollen, (B) samples where maize pollen was recovered, (C) Ca/Ti ratio from XRF data as a proxy for drought, (D) charcoal as a proxy for human-induced fire. Modified from Åkesson et al. (2020). 
Tilacancha Private Conservation Area (PCA)
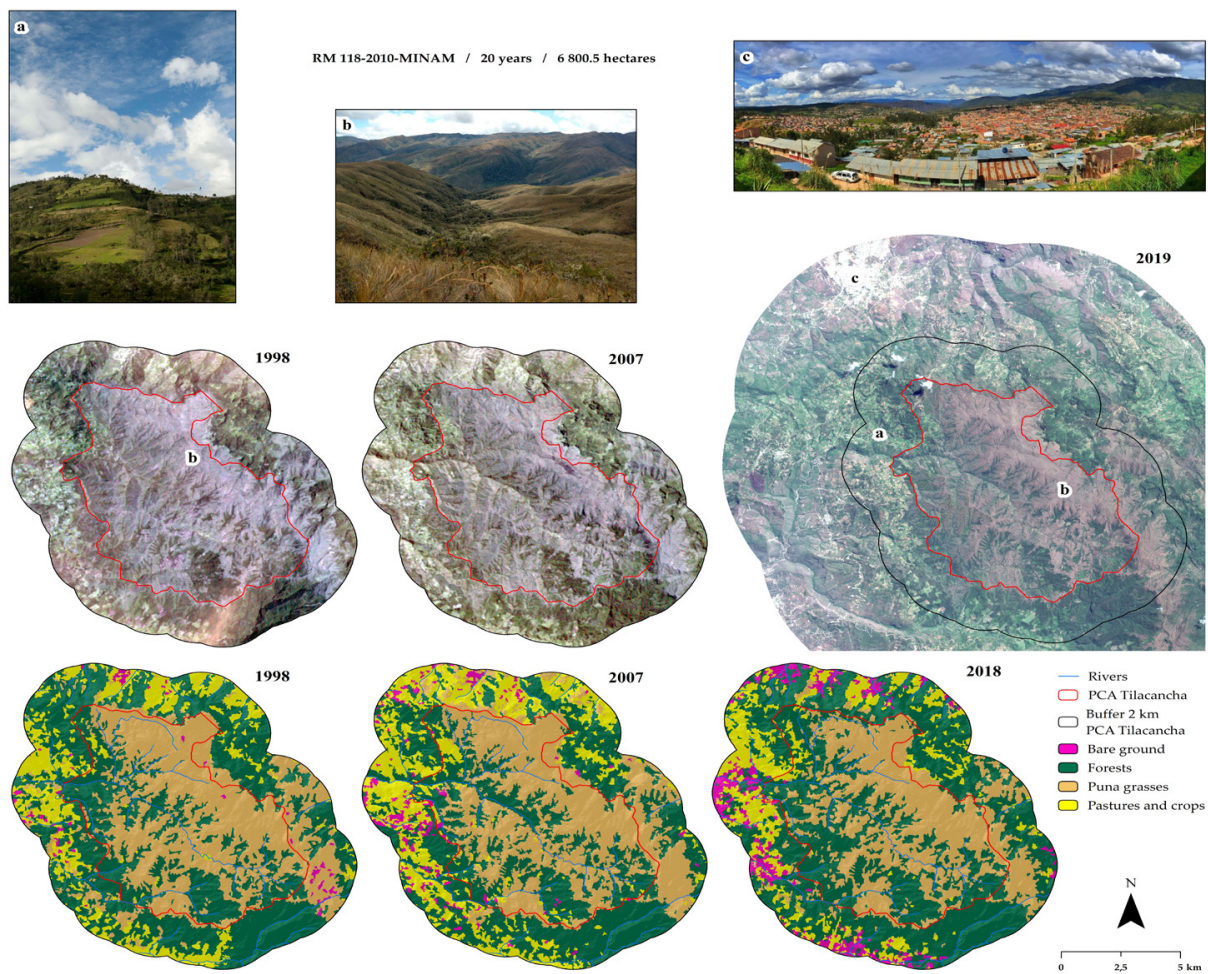

- Rivers

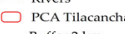
$\square$ PCA $2 \mathrm{~km}$ Bare ground Forests $\checkmark$ Pastures and crops

Figure 2: Infographic of Tilacancha in Chachapoyas. Source: N. Rojas, Landsat 5 images, Path/Row 009/064 11/28/1998 and 08/01/2007 (USGS, earthexplorer.usgs.gov). Sentinel 2A image, Path/Row 17MRP, 08/17/2019 (ESA, earthexplorer.usgs.gov). Photos (A) Conservamos por Naturaleza, Peruvian Society of Environmental Law. (B) Roque Silloa. (C) Mirador de Luya Urco (CieloChicBlog, cielochicblog.com/?p=2809). Maps of land cover and land use: E. Delgado. Photos compiled by S. Fernandez and N. Rojas.

pressure from cultivation-based communities would have also reduced the population of game animals and disproportionately removed large seed-dispersers (Aubad et al. 2010). Favored plants might have been tended to, planted, or even accidentally introduced, even at some distance from villages. Consequently, when the forests regrew, they would have been on a different successional trajectory than in an undisturbed setting (Levis et al. 2012). While species compositions changed, so too did the physical landscape, as hill slopes were modified by either earthen terracing or stream canalization.

Modern trade has accelerated landscape transformation and introduced many exotic species to the region, including African grasses, Australian Eucalyptus, and Monterrey pine. Consequently, these forests, which exist as a full gradient from "novel" communities to nearly natural ones, will respond differently to climate stimuli than their natural counterparts. Stimuli also come from the socio-ecological systems in need of applied montology (Sarmiento et al. 2017) and better conservation approaches (Bax and Francesconi 2019) to sustainability.

\section{The path to science-based ecotourism}

Today, conservation efforts are developing strategies of payment for environmental services and preservation of remnant old-growth forests in protected national, district-level or private areas. For example, among the perceived benefits of restoration of the privately held Tilacancha and Huiquilla Conservation Areas (Fig. 2) are improved water quality, prevention of mining operations that despoil landscapes, and promotion of ecotourism.
These mixed-use areas still support exotic Eucalyptus and Pinus plantations, but the restricted use of fire now allows degraded pastures to return to forest. An increase in wildlife has already been observed, and ecotourism is incentivized by the role of informed guides trained via environmental education campaigns and ecotourism investment opportunities. Indeed, the most profitable conservation option is tourism, and many investments emphasize ecotourism ventures, such as "the route of petroglyphs", "the route of mummies", and "waterfall circuits" featuring one of Peru's tallest waterfalls (Gocta), a spectacular hilltop citadel (Kuelap), and impressive mortuary sites such as the sarcophagi of Karajia and the mausoleums at Revash. Together, they create a vibrant touristic destination of "natural" and "cultural" sites that may one day may rival the Sacred Valley near Cuzco, if properly encouraged.

We argue that the only way to maintain the unique characteristics that draw ecotourists to an area is to curate the biocultural heritage and to seek to apply regenerative development strategies that confer additional resilience to landscapes in the face of the expansion of cattle grazing. We could start with restoring degraded slopes and reforesting large areas that could bring back the former TMCF, including iconic animals that attract ecotourists, such as Peru's national bird, the cock-of-the-rock (Rupicola peruviana), the spectacled bear (Tremarctos ornatus), the spatula-tailed hummingbird (Loddigesia mirabilis), the mountain lion (Puma concolor), the critically endangered yellow-tailed wooly monkey (Oreonax flavicauda) and the long whiskered owlet (Xenoglaux loweryi). Such protections require not only trained guides but also changes in management strategies by owners, as well as an about-face in popular consciousness to curve destruction of the "Ceja de Selva".

Effective management can be informed by natural fire periodicities of $>1000$ years elicited from paleoecological records and lists of taxa that should form the basis for replanting in both natural and civic settings. It is imperative that the modernization efforts encourage tourists to spend time in the city of Chachapoyas, where old native trees of the plazas have been replaced by newly planted exotic species. But perhaps one of the most valuable roles that mountain science can play is by informing the narratives and anecdotes that provide local insights and environmental appeal to the descriptions given by science-trained guides. They must provide information from montology that is accurate, enriching, and deepens the understanding of how our history shapes what we perceive to be natural in the biocultural microrefugia of the tropical Andes.

\section{AFFILIATIONS}

'Neotropical Montology Collaboratory, Department of Geography, University of Georgia, Athens, USA ${ }^{2}$ Neotropical Paleoecology Research Group, Harris Center for Science and Engineering, Florida Institute of Technology, Melbourne, USA

${ }^{3}$ Department of Earth and Space Sciences, Columbus State University, GA, USA

${ }^{4}$ Department of Anthropology, Brown University, Providence, RI, USA

Instituto de Investigaciones de Desarrollo Sustentable de la Ceja de Selva, Universidad Nacional Toribio Rodríguez de Mendoza de Amazonas, Chachapoyas, Peru

\section{CONTACT}

Fausto Sarmiento: fsarmien@uga.edu

\section{REFERENCES}

Åkesson CM et al. (2020) Nat Ecol Evol 4: 66-74 Aubad J et al. (2010) Acta Oecol 36: 396-402 Bax V, Francesconi W (2019) J Environ Manage 232: 387-396

Bush MB et al. (2015) Holocene 25: 1522-1532 Church WB, von Hagen A (2008) In: Silverman H, Isbell W (Eds) The Handbook of South American Archaeology. Springer, 903-926

Guengerich A, Berquist S (2020) Journal of Field Archaeology 45: 153-169

Guengerich A (2015) Latin American Antiquity 26 362-381

Lara Cl (2010) Antropología Cuadernos de Investigación 9: 77-90

Levis C et al. (2012) PLoS ONE 7: e48559

Matthews-Bird F et al. (2017) Holocene 27: 1707-1719

Raczka MF et al. (2018) Quat Sci Rev 205: 154-165

Sarmiento FO (2012) Contesting Páramo: Critical Biogeography of the Northern Andean Highlands. Kona Publishing, 200 pp

Sarmiento FO (2016) Engineering Mountain Landscapes: An Anthropology of Social Investment. American Indian Culture and Research Journal 40: 157-159

Sarmiento FO et al. (2017) Ann Assoc Am Geogr 107: 416-428

Schjellerup IR (2019) Acta Archaeologica 90: 135-154

Schjellerup IR et al. (2005) The Chilchos Valley revisited: Life conditions in the Ceja de Selva, Peru. The National Museum of Denmark, 424 pp

Young KR (2009) Ann Mo Bot Gard 96: 492-507 